University of Nebraska - Lincoln

DigitalCommons@University of Nebraska - Lincoln

Architectural Engineering -- Faculty Publications

Architectural Engineering and Construction,

Durham School of

\title{
8-2021
}

\section{Designing GFRP-Reinforced Tilt-up Wall Panels}

Fray F. Pozo-Lora

Marc Maguire

Follow this and additional works at: https://digitalcommons.unl.edu/archengfacpub

Part of the Architectural Engineering Commons, Construction Engineering Commons, Environmental Design Commons, and the Other Engineering Commons

This Article is brought to you for free and open access by the Architectural Engineering and Construction, Durham School of at DigitalCommons@University of Nebraska - Lincoln. It has been accepted for inclusion in Architectural Engineering -- Faculty Publications by an authorized administrator of DigitalCommons@University of Nebraska Lincoln. 


\author{
Designing GFRP-Reinforced Tilt-up Wall Panels \\ Fray F. Pozo-Lora \& Marc Maguire \\ Durham School of Architectural Engineering and Construction, \\ University of Nebraska - Lincoln, Omaha NE 68182
}

\title{
1. Introduction
}

Tilt-up construction was effectively enabled on a wide scale in 1979, when the ACI committee 551 report on Tilt-up construction was published, the Recommended Tilt-Up Wall Design, aka, the Yellow Book and the subsequent ACI-SEASC Task, aka the Green Book, and another Tilt-up design and construction manual developed by the ACI in 1988. The Tilt-up Concrete Association was created in 1986 by a group of industry professionals who had the need of an organization dedicated to the industry. ACI 551 maintains a document outlining the standard practice for contemporary Tilt-up design and construction. The ACI 551 document does not consider walls reinforced with non-ferrous reinforcement. However, recent events have made glass fiber-reinforced polymer rebar a more economical option when compared to traditional steel reinforcement. This white paper is intended to provide the unfamiliar engineer a bridge between the ACI 318, ACI 551 and ACI 440 documents to engineer a tilt-up wall including differences between GFRP reinforcement and steel reinforcement with respect to design.

\section{Behavior of flexural members reinforced with GFRP bars}

Steel, is an isotropic ductile metal extensively used in construction, mechanical, and electronic devices. Steel is often designed as elastic-perfectly plastic where it has an elastic modulus of 29,000ksi and yield stress of 60ksi. GFRP reinforcement is considered brittle-elastic with an elastic modulus often between $6,000 \mathrm{ksi}-8750 \mathrm{ksi}$ and guaranteed ultimate tensile strength between 90-150ksi. Figure 1 presents an example of the design-assumed uniaxial stress versus strain comparing traditional steel and GFRP. . 


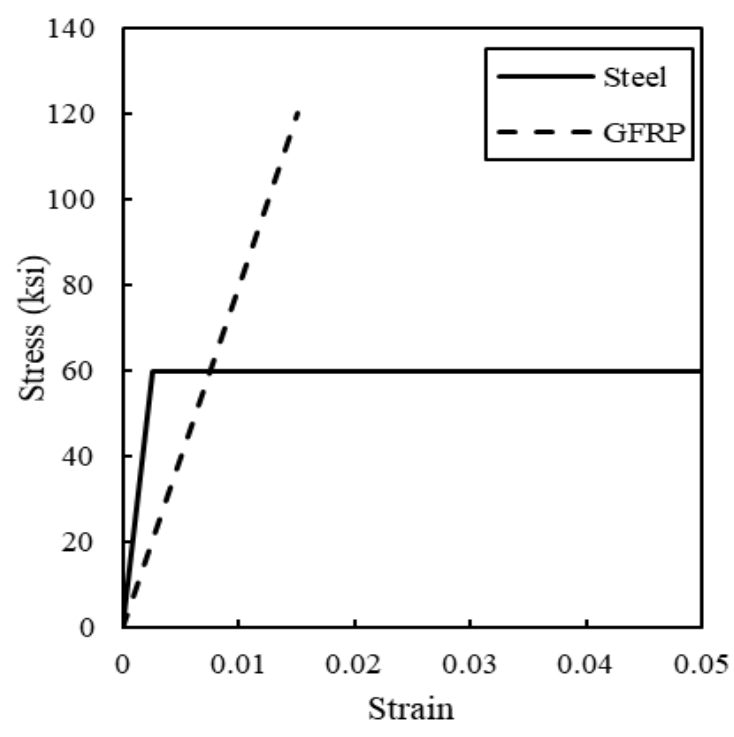

Fig. 1 Example Stress versus Strain curve for GFRP and mild steel rebar.

While GFRP reinforcement has different physical and mechanical properties the differences and behaviors are well understood by the engineering community. There are ASTM material standards for GFRP bars, namely ASTM D7957 and a complete suite of ASTM test method by which the basic properties are verified.

The following sections will illustrate the differences between steel and GFRP reinforced concrete members with a focus on slender tilt-up wall panels.

\section{Behavior of flexural members reinforced with GFRP bars}

The flexural performance of concrete members reinforced with FRP reinforcement has been studied for more than three decades. ACI 440.1R design guidance was first published in 2001 and has subsequently undergone six iterations with improvements, the current version being ACI 440.1R-15. In recent years, its considerable lightweight and lower first cost have become appealing to the construction industry due to increased labor costs and steel prices.

The preferred failure mode for FRP-reinforced concrete members in flexure is concrete crushing, contrasting the typical steel-reinforced member design, in which desirable failure mode is tensile yielding of the steel reinforcement. Tension yielding in steel-reinforced concrete provides large, well defined deformations, allowing for a warning prior to component failure. Because FRP composites are linear to elastic to failure, concrete crushing while the FRP reinforcement is not yet ruptured, results in the most ductile failure mode. Although the warnings are evident prior to failure for FRP reinforced members, such as large deformations, no reinforcement ductility is achieved as is normally seen in steel-reinforced 
concrete, where the bars display plastic deformations before concrete reaches its ultimate strain (ACI Committee 440 2015).

Many researchers have studied the behavior of FRP-reinforced concrete members in flexure. In terms of flexural performance, GFRP-reinforced beams cracking behavior at low load levels is very similar to that of steel-reinforced concrete beams. However, cracking is more extensive and width is more considerable when large loads are applied to FRP-reinforced beams compared to steel-reinforced beams (Benmokrane et al. 1996). In regard to shear performance, GFRP-reinforced members exhibit a reduced capacity when compared to the equations in the ACI code and a proper modification has been suggested previously in the literature. Another parameter that deserves attention when designing with GFRP is the effective stiffness of the member $\left(I_{e}\right)$. Members reinforced with these bars tend to yield ratios $I_{g}$ to $I_{c r}$ between 5 and 25 whereas in steel-reinforced concrete it usually ranges between 3 and 4 .

ACI 440.1R has adopted the equation proposed by (Bischoff 2005) with little modification to account of the variation of stiffness along the length of the flexural member. According to Bischoff et al. (2009), the equation introduced in the code yields "reasonable estimates of deflections" for beams and one-way slab members reinforced with FRP Bars, the latter of which is very similar to a tilt-up wall. The key point in that equation is the proper election of the correction factor, which depends on the loading type (point loads or distributed loads) and the boundary conditions (simple spans or continuous members) of the member for which the effective moment of inertia is being computed.

\section{Design of tilt-up walls reinforced with GFRP Bars}

Tilt-up walls can serve as bearing or non-bearing walls extending from the foundation system to the intermediate floors and roof. Since these elements take part of the envelope system as well, they are subjected to out-of-plane loads, which generate bending moments, and axial loads, from the roof and any intermediate floors. Tilt-up panels are slender and large second-order moments generated from the axial load that is eccentrically applied to the wall due to the deflected shape. This increase in flexural moment is also known as the $\mathrm{P}-\delta$ effect and may cause failure if not considered properly during the design process. ACI 551.2R defines the ultimate failure of a tilt-up wall as the exceedance of the maximum factored bending moment by the ultimate loads at the vicinity of the mid-height of the panel.

Tilt-up walls are routinely designed per ACI 318-19 chapter 11 with some additional guidance from ACI 551 report (ACI Committee 2015). ACI Committee 551 has devoted significant time to increase the use of Tilt-up concrete panels around the US and provide safe design guidance. In terms of design methodologies, the report 551.2R-15 (ACI Committee 2015) contains an expansion of current design provisions outlined in the ACI 318-11 and ASCE/SEI 7-10 along with design examples and 
detailed explanation of the code provisions. ACI 551.2R uses the "Alternative method for out-of-plane slender wall analysis" to develop application examples. This method consists, of computing primary moments and then finding secondary moments through iteration and convergence, see Fig. 1. In the case convergence is not achieved or the deflection does not comply with the maximum allowed by code, the panel is considered unstable or not code compliant, respectively.

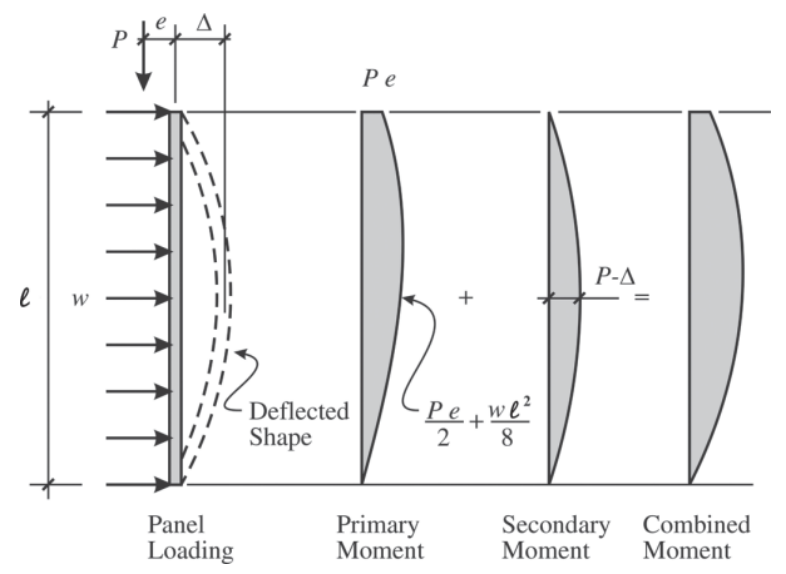

Fig. 1 Illustration of the panel design process (ACI Committee 2015).

The loading conditions mentioned above can be broken down into three essential deformation cases. The first one is the maximum deflection due to lateral load alone, which is depicted in Fig. 2a. The second one is the deformation due to the constant moment case that is due to axial load at the top of the panel multiplied by the eccentricity of the load itself, see Fig. $2 \mathrm{~b}$. The third and most important is the second order deformation analysis of the axial load, which is no longer aligned with the center of gravity of the cross-section, see Fig. 3. 


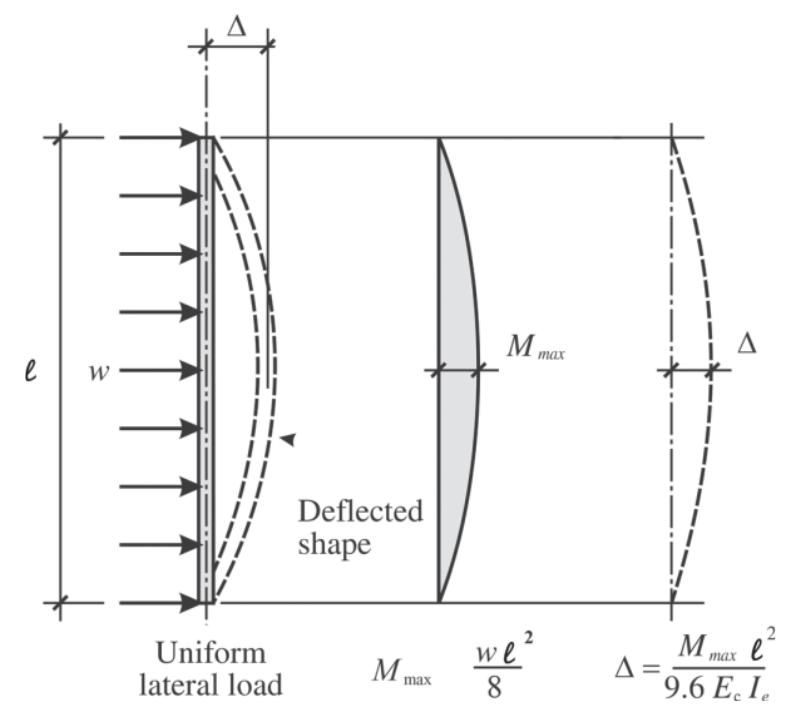

(a)

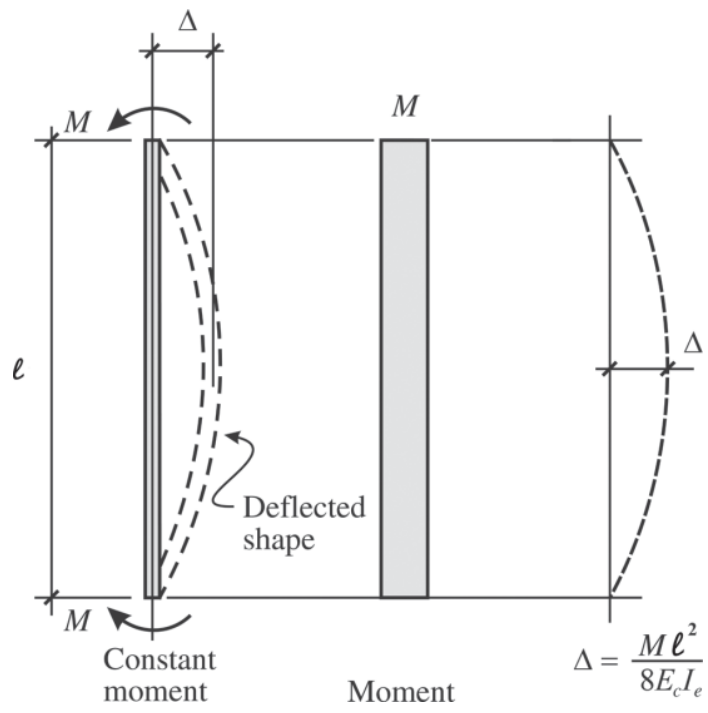

(b)

Fig. 2 Out-of-plane deformation due to wind load alone (a), and constant lateral moment $(b)$ (ACI Committee 2015).

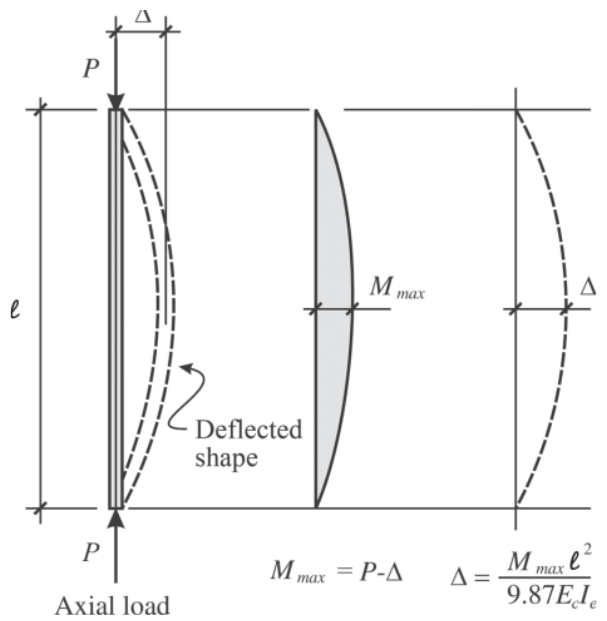

Fig. 3 Deformation due to concentrical axial load alone (ACI Committee 2015).

The inputs of the method are the loads, eccentricity, panel dimensions, concrete and steel mechanical properties, steel reinforcement amount and position in the cross-section, and boundary conditions. However, as of this writing, there is no specific guidance for designing FRP-reinforced tilt-up walls and the user needs go to ACI 440 to find FRP-specific equations regarding flexural behavior and long-term performance. However, as mentioned above, ACI 440 and the literature provide the means for design of tilt-up walls using GFRP reinforcement. 
Although ACI 440.1R-15 does not contain or address the behavior of slender wall panels design, the report contains important information pertaining to the behavior of GFRP-reinforced concrete beams and slabs subjected flexure (ACI Committee 440 2015). In case of slender walls, their behavior resembles the one of lightly reinforced one-way slabs under flexural loads with axial load on its edge. As mentioned earlier, the response of these walls is largely affected by the effective moment of inertia chosen for the calculations. This is the main concept that is combined with the ACI 318-19 in the following step-by-step procedure.

Procedure on the design of tilt-up walls reinforced with GFRP.

The following list provides an overview of how one might approach the design of a tilt-up wall reinforced with GFRP bars. Instead of following the classical reinforced concrete design steps outlined in the ACI 318-19, the reader is encouraged to follow ACI 440.1R-15 closely for computing both strength and service. Since the process is iterative, it is common to go through multiple times to find the optimal thickness and reinforcement of the panel. The steps needed to design the panel are the following:

(a) Select the panel geometry, concrete properties, and the reinforcing area and distance to the extreme fiber in tension. The ACI 551.2R recommends starting with a panel thickness of $l c / 50$ for a section with a single layer of reinforcement and $l c / 65$ for a section with two layers of reinforcement.

(b) Compute ultimate and service loads, including axial and out-of-plane loading. ACI 318-19 contains a set of seven load combinations on Table 5.3.1; however, the loads must be taken from the adopted ASCE/SEI 7 Standard in the corresponding jurisdiction.

(c) Determine the nominal and ultimate strength. This is probably one of the most critical steps in the design of the panel since it involves switching from the conventional reinforced concrete basic assumption of a tension-controlled behavior to a compression-controlled behavior. Since the desired failure mode in FRP-reinforced members in flexure is the failure of the compression block, the code has been developed with this emphasis. Unlike steel-reinforced members, this results in a brittle failure mode but at the same time it provides more warning in terms of larger deformations and postpeak behavior than a tension-controlled failure (Nanni 1993). Although this explanation seems obvious to designers, the code allows for both tensile rupture of FRP and concrete crushing failure modes. The main assumptions from steel-reinforced members, such as maximum concrete strain is 
0.003 and a linear strain profile, are applicable to FRP-reinforced members, with the exception that FRP is linearly elastic. Therefore, if one performs a strain compatibility analysis to derive a balanced reinforced ratio considering the above mentioned assumptions per (ACI Committee 440 2015), it yields the equation contained in (1):

$$
\rho_{f b}=0.85 \beta_{1} * \frac{f_{c}{ }^{\prime}}{f_{f u}} * \frac{E_{f} \epsilon_{c u}}{E_{f} \epsilon_{c u}+f_{f u}}
$$

Where:

- $\quad \rho_{f b}=$ Balanced reinforcement ratio

- $\quad \beta_{1}=$ Whitney stress block factor

- $f_{c}^{\prime}=$ Compressive strength of concrete

- $f_{f u}=$ Design tensile strength of FRP

- $E_{f}=$ Design modulus of elasticity of FRP

- $\epsilon_{c u}=$ Ultimate concrete strain $=0.003$

If the reinforcement ratio is $\rho_{f}>\rho_{f b}$, then the member main failure mode is concrete crushing and it will break before the GFRP does. This case has a relatively simple solution, as it is shown in Equations (2) through (4):

$$
\begin{gathered}
f_{f}=\left(\sqrt{\frac{\left(E_{f} \epsilon_{c u}\right)^{2}}{4}+\frac{0.85 \beta_{1} f_{c}^{\prime}}{\rho_{f}} E_{f} \epsilon_{c u}}-0.5 E_{f} \epsilon_{c u}\right) \leq f_{f u} \\
a=\frac{A_{f} f_{f}}{0.85 f_{c}^{\prime} b} \\
M_{n}=A_{f} f_{f}\left(d-\frac{a}{2}\right)
\end{gathered}
$$


Where:

- $f_{f}=$ FRP tensile stress

- $\rho_{f}=$ FRP reinforcement ratio

- $\quad a=$ Depth of compression block

- $A_{f}=$ Area of FRP reinforcement

- $\quad b=$ Width of beam

- $M_{n}=$ Nominal moment capacity of the section

- $\quad d=$ Depth of FRP from top of compression block

When Equations (2) and (3) are substituted into Equation (4) to solve for the moment capacity it yields the tension-controlled case where $\rho_{f}<\rho_{f b}$, which is allowed to take a lower bound value according to ACI 440.1R-15 (see Equations (5) and (6)):

$$
\begin{gathered}
c_{b}=\left(\frac{\epsilon_{c u}}{\epsilon_{c u}+\epsilon_{f u}}\right) d \\
M_{n}=A_{f} f_{f u}\left(d-\frac{\beta_{1} c_{b}}{2}\right)
\end{gathered}
$$

Where:

- $\epsilon_{f u}=$ FRP rupture strain

- $c_{b}=$ Depth to neutral axis at balanced condition

According to the ACI 440-15, the factored resistance is obtained by multiplying the nominal moment capacity, $M_{n}$, by the corresponding resistance factor, $\phi$ (see Equation (7)). This factor is graphically shown in Fig. 4.

$$
\phi=\left\{\begin{array}{c}
0.55 \text { for } \rho_{f} \leq \rho_{f b} \\
0.3+0.25 \frac{\rho_{f}}{\rho_{f b}} \text { for } \rho_{f b}<\rho_{f}<1.4 \rho_{f b} \\
0.65 \text { for } \rho_{f} \geq 1.4 \rho_{f b}
\end{array}\right.
$$

Where:

- $\phi=$ Strength reduction factor. 


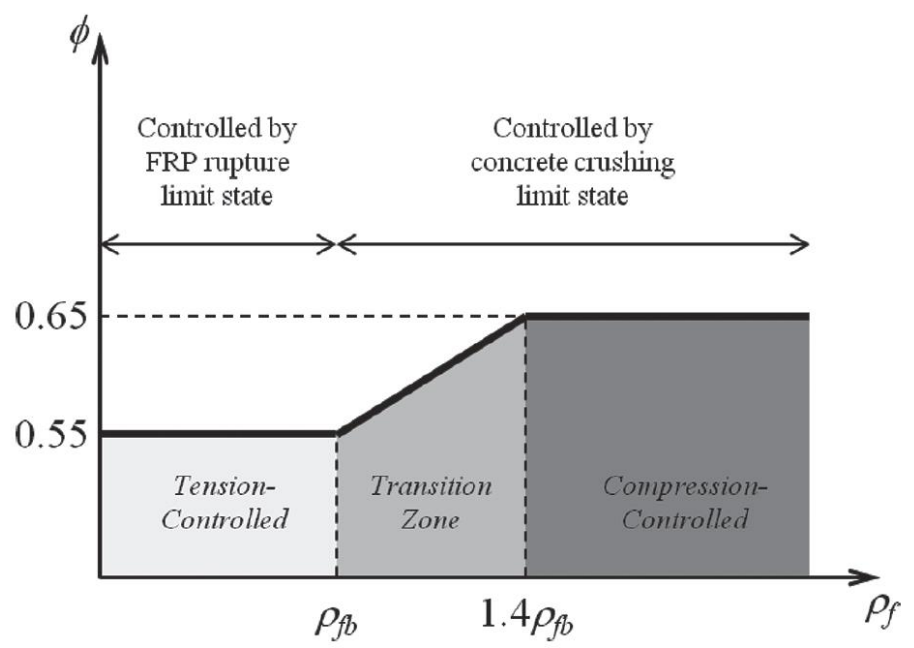

Fig. 4 Resistance factor of FRP-reinforced concrete (ACI Committee 440 2015)

It is important to note that the $f_{f u}$ property needs to be multiplied by multiple factors before being used in equation 2-6. One of them is the called environmental factor $\left(C_{E}\right)$, and it considers the type of exposure that the member will experience during its service life. The different types of environmental factors are displayed in Table 1, for the three main types of FRP reinforcement used in concrete construction.

Table 1 FRP Environmental Reduction Factors (ACI Committee 440, 2015)

\begin{tabular}{ccc}
\hline Exposure Condition & Fiber Type & $\begin{array}{c}\text { Environmental Reduction } \\
\text { Factor } \mathbf{C}_{\mathbf{E}}\end{array}$ \\
\hline \multirow{2}{*}{ Concrete not exposed to } & Carbon & 1.0 \\
earth and weather & Glass & 0.8 \\
& Aramid & 0.9 \\
\hline \multirow{2}{*}{ Concrete exposed to } & Carbon & 0.9 \\
earth and weather & Glass & 0.7 \\
& Aramid & 0.8 \\
\hline
\end{tabular}

In tilt-up wall panels, the presence of axial loads serves to generally increase the moment strength because they are low compared to the total concrete area. Rather than require an engineer to perform a strain compatibility analysis, the commentary offers an alternative by allowing the calculation of an effective area of steel, $A_{s e, w}$. The purpose of $A_{s e, w}$ is to account for the additional moment strength provided by the axial compression in a way that avoids having the designer to perform an axial and moment interaction analysis through strain compatibility (Mays et al. 2013), but its origins are unclear. 
For an FRP reinforced tilt-up wall, which is already limited to an axial stress below $0.06 f^{\prime}$ by ACI 31819 , it is likely that the presence of axial loads below this limit will serve to slightly increase the moment strength - likely less than a steel-reinforced wall - thus making it conservative to ignore the $A_{s e, w}$ term and assume the axial load provides no benefit. The engineer must exercise judgment as to whether this is acceptable and is encouraged to perform a strain compatibility analysis including the contribution of the axial force when calculating the moment strength.

(d) Determine the service and ultimate load deflections using the corresponding equations for the boundary conditions of the panel. Employ equations (8) through (12) to account for the effects of cracking on the panel. By definition, an uncracked member has a moment of inertia equal to the gross moment of inertia of the section, $I_{g}$. From concrete fundamentals, cracking occurs when the applied flexural moment equals or exceed the cracking resisting moment of the section. As a consequence of the cracking, the moment of inertia deteriorates and causes a stiffness reduction. Using the approach outlined in (Branson 1977). the cracked moment of inertia for a singly reinforced section can be computed using the following equations:

$$
\begin{gathered}
I_{c r}=\frac{b d^{3}}{3} k^{3}+n_{f} A_{f} d^{2}\left(1-k^{2}\right) \\
k=\sqrt{2 \rho_{f} n_{f}+\left(\rho_{f} n_{f}\right)^{2}}-\rho_{f} n_{f}
\end{gathered}
$$

Where:

- $A_{f}=$ Area of reinforcement.

- $b=$ Width of the cross-section.

- $d=$ Depth of reinforcement in the cross-section.

- $I_{c r}=$ Cracked moment of inertia.

- $k=$ Ratio of depth of neutral axis to reinforcement depth.

- $n_{f}=$ Ratio of modulus of elasticity of FRP bars to modulus of elasticity of concrete.

- $\rho_{f}=$ Reinforcement ratio

In general, the stiffness in flexure of a cracked member fluctuates between $E_{c} I g$ and $E_{c} I_{c r}$, where $E_{c} I_{g}$ represents the full stiffness of the member when the service moment does not exceed the cracking moment, and $E_{c} I_{c r}$ represents the fully cracked stiffness. Since the stiffness value for a cracked member is always in between the aforementioned values, Branson (1977) introduced the concept of effective moment of inertia $\left(I_{e}\right)$ so that one can account for two different things happening in the members when 
they are transitioning between $I_{g}$ to $I_{c r}$. The first one is the tensioning stiffening phenomenon ${ }^{1}$, and the second one is the variation of the stiffness along the length of the member. According to Branson (1963), the average effective moment of inertia for a rectangular and T-beam is:

$$
\text { Avg. } I_{\text {eff }}=\left[\left(\frac{M_{c r}}{M_{\max }}\right)^{3}\right] I_{g}+\left[1-\left(\frac{M_{c r}}{M_{\max }}\right)^{3}\right] I_{c r}
$$

Where:

- $I_{c r}=$ Cracked moment of inertia.

- $I_{g}=$ Gross moment of inertia.

- Avg. $I_{e f f}=$ average effective moment of inertia

- $M_{c r}=$ Cracking moment.

- $M_{\max }=$ Maximum applied moment $>M_{c r}$.

However, equation (10)(8) only works properly when the ratio between Ig and Icr is low (3-4). In the case of GFRP-Reinforced members, this ratio often ranges between 5 and 25 (Bischoff and Scanlon 2007). Many researchers developed equations to overcome the shortcoming introduced by Branson's equation in the computation of deformations of FRP-reinforced members, most of which were empirical (Benmokrane et al. 1996; Nawy and Neuwerth 1977; Yost et al. 2003). ACI 440.1R has adopted the equation proposed by (Bischoff 2005) with a little modification to account of the variation of stiffness along the length of the flexural member.

$$
I_{e}=\frac{I_{g}}{1-\gamma\left(\frac{M_{c r}}{M_{a}}\right)^{2}\left[1-\frac{I_{c r}}{I_{g}}\right]} \leq I_{g}
$$

Where:

- $I_{c r}=$ Cracked moment of inertia.

- $I_{g}=$ Gross moment of inertia.

- $I_{e}=$ average effective moment of inertia.

- $M_{c r}=$ Cracking moment.

- $M_{a}=$ Applied moment $>M_{c r}$.

- $\gamma=$ Correction factor to account for stiffness variation along the length of the member.

\footnotetext{
${ }^{1}$ Tension stiffening refers to the concrete participation, due to bond between the rebar and the concrete, in between cracks to resist tensile stresses in a cracked member.
} 
According to Bischoff et al. (2009), Equation (11) yields "reasonable estimates of deflections" for beams and one-way slab members reinforced with FRP Bars. The key point in that equation is the proper election of the correction factor $(\gamma)$, which depends on the loading type (point loads or distributed loads) and the boundary conditions (simple spans or continuous members) of the member for which the effective moment of inertia is being computed. ACI $440.1 \mathrm{R}$ recommends $\gamma=1.72-0.72\left(M_{c r} / M_{a}\right)$ for a simple span member with a distributed load. In the case of continuous members, the guide recommends using a weighted average of the effective moment of inertia computed using the critical moment at positive and negative sections (support and midspan vicinity). For example, the case of a beam with both ends continuous it can be expressed as $I_{e}=0.70 I_{e+}+0.15\left(I_{e 1-}+I_{e 2-}\right)$, whereas when only one end is continuous it can be computed based on the location of the maximum moment outside of the support.

ACI 551 and ACI 318-19 enforce a concrete rupture stress of $5 \sqrt{f^{\prime}}$ and the cracking moment capacity of the section can be determined using Equation (12). Typically, if the applied moment is larger than the cracking moment, then the effects of cracking should be included in the analysis using equation (11). However, due to the manner in which tilt-up walls are constructed, lifted and assembled, it is common to assume that the section is always cracked, but proper calculation of the cracking moment is essential to the post-cracking behavior based on Equation (11).

$$
M_{c r}=\frac{5 \lambda \sqrt{f^{\prime}} I_{g}}{y_{t}}
$$

Where:

- $f^{\prime}{ }_{c}=$ Specified concrete compressive strength at 28 days.

- $\lambda=$ Lightweight concrete correction factor.

- $I_{g}=$ Gross moment of inertia.

- $y_{t}=$ distance from the centroid of the section to the extreme fiber in tension.

(e) Verify that the wall is adequate for strength, if not modify section properties and go to step (a). As it was noted at the beginning of section 4 , the bending stiffness evaluation consist of three steps that ultimately lead to deriving the maximum deflection in the panel, which consequently yields the following expression for computing the maximum deflection $\left(\Delta_{\max }\right)$ and the bending stiffness $\left(K_{b}\right)$. 


$$
\begin{gathered}
\Delta_{\text {max }}=\frac{5 M_{\text {max }} l^{2}}{48 E_{c} I_{e}}=\frac{M_{\max }}{K_{b}} \\
K_{b}=\frac{48 E_{c} I_{e}}{5 l^{2}}=\frac{9.6 E_{c} I_{e}}{l^{2}}
\end{gathered}
$$

The previous two expressions, (13) and (14), will overestimate the deflection and maximum moment slightly if the $P-\delta$ moment is larger than the moments due to all loads, and their solution can be obtained by iteration. Iteration is allowed by ACI 318-19 11.8.3.1 step (a) when adding a 0.75 factor to the denominator in expression (13). Therefore, the ultimate moment will yield the expression for $\mathrm{Mu}$ contained in (15), with $\Delta_{u}$ as expressed in (16). Alternatively, one can use the part (b) of the same ACI section, which uses the expression contained in (17).

$$
\begin{gathered}
\mathrm{M}_{u}=\frac{5 M_{\text {max }} l^{2}}{(0.75) 48 E_{c} I_{e}} \\
\mathrm{M}_{u}=\mathrm{M}_{u a}+P_{u} \Delta_{u} \\
\mathrm{M}_{u}=\frac{M_{u a}}{\left(1-\frac{5 P_{u} l_{c}^{2}}{(0.75) 48 E_{c} I_{c r}}\right)}
\end{gathered}
$$

ACI 318 has also adopted the moment magnifier method for evaluation of P-delta effects. Although this method produces the same values as the ones in equation (15), some engineers think they are different (ACI Committee 2015). If one follows section 6.6.4 of ACI 318-19, and employs the equation (14), it yields:

$$
\begin{gathered}
\mathrm{M}_{\text {max }}=\mathrm{M}_{a}+\frac{P \mathrm{M}_{\max }}{K_{b}} \\
\mathrm{M}_{\text {max }}=\mathrm{M}_{a}\left\{\frac{1}{1-\frac{P}{K_{b}}}\right\}=\mathrm{M}_{a} \delta_{b}
\end{gathered}
$$




$$
\delta_{b}=\left\{\frac{1}{1-\frac{P}{K_{b}}}\right\}
$$

(f) Verify that the wall is adequate for sustained loading, if not modify section properties and go to step (a). Like concrete in compression, FRP reinforcement can experience creep rupture under excessive sustained loads. Table 2Error! Reference source not found. contains the limits which shall be checked for different fiber types per ACI 440. Sustained loads should be accounted for in the second order analysis moment amplification analysis along with a reasonable assumption for initial bowing and assuming the wall is cracked, thus using Ie for calculations. ACI 551.2R-10 Section 6.2 indicates a minimum initial bowing shall be considered at $h / 400$.

Table 2 Long-Term Stress Reductions (ACI Committee 440 2015)

\begin{tabular}{cccc}
\hline Fiber Type & GFRP & AFRP & CFRP \\
\hline Creep Rupture Stress Limit, $f_{f, s u s}$ & $0.2 f_{f u}$ & $0.3 f_{f u}$ & $0.55 f_{f u}$ \\
\hline
\end{tabular}

(g) Verify that the wall is adequate for service deflections, if not modify section properties and go to step (a). Although ACI code does not contain any limit on panel deflection, the literature considers that a maximum deflection for service loads of $l c / 150$ should be used to set a limit on the out-of-plane deformation (ACI-SEASC Task 1982). Computing the maximum out-of-plane deflection also involves an iterative process similar to the one outlined in step (e) of this section, but only using service load combinations. The ASCE/SEI 7 Appendix C contains limit states sufficient to check service deflections. Specifically, D0.5L+W $\mathrm{W}_{\mathrm{a}}$ where $\mathrm{W}_{\mathrm{a}}$ is the service wind loading presented in ASCE/SEI 7 Appendix C. ACI 318 Section 14.8.4 indicates D+0.5L+0.7E for service seismic loading. 
Once the panel has been designed for flexure and service, other aspects such as connection design, bearing of framing elements, and lifting checks must be performed outside this routine using caution and engineering judgement.

\section{Flowchart}

The following flowchart is provided for informational purposes and intended to quickly give the engineer a visual of the information provided in the previous section. Application of this procedure to all panels may not be appropriate, it is the responsibility of the engineer to determine when and how this process requires deviation. 


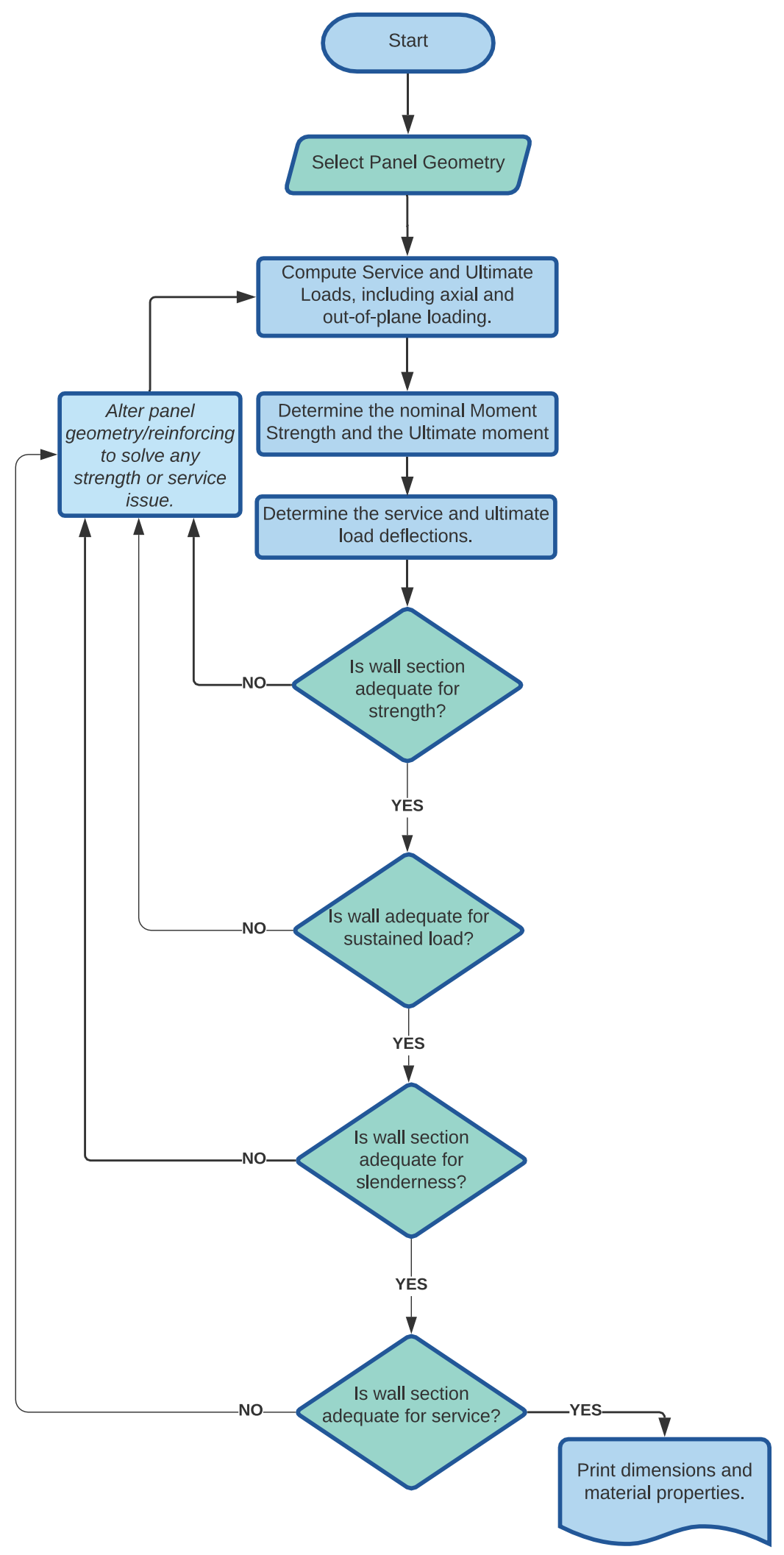

Fig 7 Flowchart for GFRP Tilt-up Panel Design 


\section{References.}

ACI-SEASC Task. (1982). Test Report on Slender Walls. Los Angeles, CA.

ACI Committee. (2015). 551.2R-15 Guide for the Design of Tilt-Up Concrete Panels. Technical Documents.

ACI Committee 318. (2019). ACI 318-19 Requisitos de Reglamento para Concreto Estructural. (ACI (American Concrete Institute), ed.), American Concrete Institute, Farmington Hills.

ACI Committee 440. (2015). "ACI 440R-15: Guide for the Design and Construction of Structural Concrete Reinforced with Fiber-Reinforced Polymer Bars."

Benmokrane, B., Masmoudi, R., and Chaallal, 0. (1996). "Flexural Response of Concrete Beams Reinforced with FRP Reinforcing Bars.” Structural Journal, 93(1).

Bischoff, P. H. (2005). "Reevaluation of deflection prediction for concrete beams reinforced with steel and fiber reinforced polymer bars." Journal of structural engineering, American Society of Civil Engineers, 131(5), 752-767.

Bischoff, P. H., Gross, S., and Ospina, C. E. (2009). "The story behind proposed changes to ACI 440 deflection requirements for FRP-reinforced concrete." Special Publication, 264, 53-76.

Bischoff, P. H., and Scanlon, A. (2007). "Effective Moment of Inertia for Calculating Deflections of Concrete Members Containing Steel Reinforcement and Fiber-Reinforced Polymer Reinforcement." ACI Structural Journal, 104(1), 68-75.

Branson, D. E. (1963). Instantaneous and time-dependent deflections of simple and continuous reinforced concrete beams. Alabama. State Highway Department.

Branson, D. E. (1977). Deformation of Concrete Structures. McGraw-Hill, New York.

Mays, T. W., Steinbicker, J. J., and Association, T.-U. C. (2013). Engineering Tilt-Up. Tilt-Up Concrete Association.

Nanni, A. (1993). "Flexural behavior and design of RC members using FRP reinforcement." Journal of structural engineering, American Society of Civil Engineers, 119(11), 33443359.

Nawy, E. G., and Neuwerth, G. E. (1977). "Fiberglass reinforced concrete slabs and beams." Journal of the Structural Division, 103(ASCE 12762 Proceeding).

Yost, J. R., Gross, S. P., and Dinehart, D. W. (2003). "Effective moment of inertia for glass fiber-reinforced polymer-reinforced concrete beams." Structural Journal, 100(6), 732-739. 